\title{
Time Dependent Erythrocyte Morphometric Changes of Prolonged Stored Blood and its Effect on Target Post-transfusion Haematocrit of Splenectomised Mongrel Dogs
}

\author{
N.H. Okereke', R.I. Udegbunam¹, S.O. Udegbunam¹, T.H. Ezeobialu'1, K.E. Ezenwaka²
}

10.18805/IJAR.B-1357

\begin{abstract}
Background: Mean values of erythrocytic morphometric parameters of very old blood and its effect on the target post-transfusion haematocrit changes of splenectomised dogs was studied.

Methods: Two hundred and fifty milliliters of blood each were drawn from healthy dogs $(n=6)$ into citrate phosphate dextrose adenine-1 anticoagulated blood bags, preserved for 35 days for the evaluation of erythrocyte morphometric and viability parameters. Thereafter, twenty adult male splenectomised dogs were randomly assigned into 5 groups $(n=3)$. Post-splenectomy, 4, 14, 21 and 28 day old blood (DOB) were transfused to groups II-V while group I animals were not transfused. Intraoperative blood loss was determined during the surgery while post-transfusion, animals haematocrit were assayed and used to calculate the targeted haematocrit.

Result: Findings revealed irreversible progressive time dependent morphometric changes by day 14 of blood storage. Hence, it is recommended that for transfusion purposes, 4 DOB should be the hallmark as it achieved the desired haematocrit and no morphometric changes were observed from it.
\end{abstract}

Key words: CPDA-1, Erythrocyte, Hematocrit, Morphometric, Trypan blue.

\section{INTRODUCTION}

As the main function of erythrocytes are to transport oxygen to tissues, carbon dioxide out of tissues and buffering of hydrogen ions; the energy utilized by these erythrocytes in maintaining biochemical, enzymatic, biomechanical and other functions does so to optimize oxygen delivery to tissues (Cunbo et al., 2017). For them to carry out these functions effectively, they are armed with both external and internal cellular structural proteins (Cunbo et al., 2017).

The structural components of red blood cells (RBC) together with Nicotinamide Adenine Dinucleotide Phosphate (NADPH) help to protect RBC against in-vivo oxidative injury that will lead to biomechanical alterations and resultant damage to the blood with defective functions (Hogman et al., 1999). The sites of damage are the cytoskeletal proteins embedded in the erythrocyte membrane. These membrane changes cause the RBC to be fragile with resultant increase in osmotic fragility (Wehrli, 2012). The efforts and investigations ongoing for the past 4-5 decades were to maintain the corpuscular integrity and viability during prolonged storage that will translate to function following transfusion. This however prolonged storage time to 42 days following addition of phosphate, adenine and glucose preserved at $2-6^{\circ} \mathrm{C}$ (Wehrli, 2012). However, some researchers had hypothesized that prolonged storage in assisted storage medium could result to increased mean hemolysis coupled with irreversible biomechanical changes that leads to decrease in the efficiency of stored blood and decrease in their ability to act their required role after transfusion.
1Department of Veterinary Surgery, Faculty of Veterinary Medicine, University of Nigeria, Nsukka, Nigeria.

2Department of Veterinary Anatomy, Faculty of Veterinary Medicine, University of Nigeria, Nsukka, Nigeria.

Corresponding Author: N.H. Okereke, Department of Veterinary Surgery, Faculty of Veterinary Medicine, University of Nigeria, Nsukka, Nigeria. Email: nnamdi.okereke@unn.edu.ng

How to cite this article: Okereke, N.H., Udegbunam, R.I., Udegbunam, S.O., Ezeobialu, T.H. and Ezenwaka, K.E. (). Time Dependent Erythrocyte Morphometric Changes of Prolonged Stored Blood and its Effect on Target Post-transfusion Haematocrit of Splenectomised Mongrel Dogs. Indian Journal of Animal Research. DOI: 10.18805/IJAR.B-1357.

Submitted: 11-03-2021 Accepted: 06-08-2021 Online: 18-09-2021

Before any transfusion with preserved blood over a long period of time is carried out, it is always desirous that the blood should have negligible and reversible haematological, biochemical, inflammatory and biomechanical changes. However, till date, there is paucity of data on the associated time dependent erythrocytic morphometric changes and its effect on the target post-transfusion haematocrit changes of splenectomised dog.

\section{MATERIALS AND METHODS}

\section{Ethics}

The experimental protocols were approved by the Institutional Animal Care and Use Committee of the Faculty 
of Veterinary Medicine, University of Nigeria, Nsukka (IACUC, FVM UNN).

\section{Time dependent erythrocytic morphometric changes}

Commercially available human blood bags (Ritcher®, China) for infants $(250 \mathrm{mls})$ was used to asceptically collect blood from 10 healthy blood donor dogs according to standard blood bank procedures. The blood was preserved in a solar operated refrigerator at $4^{\circ} \mathrm{C}$ for 35 days and samples were withdrawn aseptically on days $0,7,14,21,28$ and 35 for the investigation of haematocrit value as described by Cheesbrough (2006), morphometric parameters (erythrocyte diameter, circumference and surface) as previously described by Adili and Melizi (2014) and erythrocyte viability as described by Klaus et al. (2005).

Effect of different ages of stored blood on posttransfusion desired haematocrit in splenectomised dogs

Twenty (20) adult (between 3-4 years) apparently healthy male dogs was used for this study. They were housed in the Department of Veterinary Surgery kennel for 14 days. During acclimatization, they were screened for gastro-intestinal parasites and blood borne diseases. The dogs were routinely de-wormed and vaccinated, fed with commercial dog food (Jo-Jo ${ }^{\circledR}$ France). Water was provided ad libitum. Twelve hours to the surgery, food was withheld while water was provided till the time of the surgery. Thereafter, the dogs were typed using canine rapid quick typing test kit (Alveida ${ }^{\circledR}$ France). Blood for transfusion was obtained from twenty donor dogs weighing between $25-35 \mathrm{~kg}$. The donor dogs were typed, screened for gastro-intestinal and blood borne parasites. Care was taken to use dogs with good temperament. Blood collected were preserved in the refrigerator at $4^{\circ} \mathrm{C}$ for different days (days 4, 14, 21 and 28).

\section{Experimental protocol}

The dogs were splenectomised and then randomly assigned to 5 groups of 4 dogs each. Post splenectomy, $120 \mathrm{mls}$ of 4 , 14,21 and 28 DOB were transfused to groups II, III, IV and $\checkmark$ while group I animals were not transfused. Transfusion was carried out at $10 \mathrm{mg} / \mathrm{kg} / \mathrm{hour}$ for 40 minutes and thereafter, it was increased to $15 \mathrm{mg} / \mathrm{kg} / \mathrm{hour}$. The anaesthetic protocol used was $25 \mathrm{mg} / \mathrm{kg}$ of ketamine $\mathrm{HCL}$ after premedicating with $2.0 \mathrm{mg} / \mathrm{kg}$ xylazine.

\section{Intra-operative determination of blood loss}

Excised spleen was weighed immediately post removal with a metlers weighing balance and the weight recorded. Thereafter, $4 \mathrm{ml}$ of adrenarline (Serenaline ${ }^{\circledR}$ China) was injected at different parts of the spleen in order to exsanguinate the spleen. Repeat weight determination of the exsanguinated spleen was done 20 minutes after. The difference between the engorged spleen and the exsanguinated spleen was noted and recorded. Clean gauze with a known weight was used to drain all the blood that was let out during the surgery. The weight difference between the plain gauze and soaked gauze with blood was noted and recorded too.

\section{Desired haematocrit validation}

this was determined as previously described by Haldane et al. (2004).

\section{Statistical study}

Mean \pm Standard error of mean were determined for the variable generated on each storage day. Data collected were statistically analysed using one way analysis of variance. The Least Significant Difference (LSD) post hoc test was used to separate the variant means at $p<0.05$ as statistically significant.

\section{RESULTS AND DISCUSSION}

Making extrapolations from human studies to what happens in animals has been a misleading diagnostic tool for Veterinarians. Whole blood stability following storage is defined as the capability of blood to retain the initial value of a measured quantity for a defined period within specific limits when preserved under defined con-ditions. The results of the studied parameters showed an ongoing biomechanical metabolism following storage. Morphometric studies of red blood cells have been the subject of recent several studies in various animal species (Adili et al., 2016) together with morphologic alterations (Ibrahim et al., 2016) and vitality information (Cunbo et al., 2017) for diagnostic purposes. Morphometric changes is based on linear measurements of erythrocyte sizes (diameter, surface and circumference) (Adili et al., 2016).

The statistical significance of the experimental data obtained from the erythrocyte parameters (diameter, circumference and surface) was indicated in Table 1. The erythrocyte diameter, circumference and surface findings on day 0 ps showed no significant $(p>0.05)$ variation when compared with the values obtained on days 7 and $28 \mathrm{ps}$ but significantly $(p<0.05)$ smaller to that of day 35 . The findings on days 14 and 21 were significantly $(p<0.05)$ smaller to that of the base value with no significant $(p>0.05)$ variation between them. This could be due to compromised membrane integrity leading to loss of fluids. But by day 35 , there could be influx of fluids that inadvertently interfere and

Table 1: Changes in the mean morphometric indices of RBC of SCB in CPDA-1.

\begin{tabular}{lccc}
\hline Day & $\begin{array}{c}\text { Diameter } \\
(\mu \mathrm{m})\end{array}$ & $\begin{array}{c}\text { surface } \\
(\mu \mathrm{m})\end{array}$ & $\begin{array}{c}\text { Circumference } \\
(\mu \mathrm{m})\end{array}$ \\
\hline 0 & $7.13 \pm 0.11^{\mathrm{a}}$ & $40.33 \pm 1.23^{\mathrm{a}}$ & $22.44 \pm 0.34^{\mathrm{a}}$ \\
7 & $6.73 \pm 0.09^{\mathrm{a}}$ & $35.71 \pm 1.01^{\mathrm{a}}$ & $21.13 \pm 0.29^{\mathrm{a}}$ \\
14 & $5.38 \pm 0.13^{\mathrm{b}}$ & $23.07 \pm 1.05^{\mathrm{b}}$ & $16.89 \pm 0.39^{\mathrm{b}}$ \\
21 & $5.24 \pm 0.07^{\mathrm{b}}$ & $21.48 \pm 0.59^{\mathrm{b}}$ & $16.38 \pm 0.23^{\mathrm{b}}$ \\
28 & $7.22 \pm 0.23^{\mathrm{a}}$ & $4.44 \pm 2.67^{\mathrm{a}}$ & $22.60 \pm 0.72^{\mathrm{a}}$ \\
35 & $7.83 \pm 0.15^{\mathrm{c}}$ & $48.41 \pm 1.96^{\mathrm{c}}$ & $24.59 \pm 0.48^{\mathrm{c}}$ \\
\hline
\end{tabular}

1.Different superscripts $a, b, c$ in a column indicates a significant different between the mean at the level of probability: $p<0.05$. 
Time Dependent Erythrocyte Morphometric Changes of Prolonged Stored Blood and its Effect on Target Post-transfusion...

induce some cytoplasmic and morphometric changes and on the extreme provoke degranulation of red cells (Adili and Melizi, 2014).

During storage, red blood cells undergo marked morphological changes (lbrahim, 2008). Findings revealed about $25-50 \%$ spherocytes with $64-73 \%$ dicosyte by day 14 ps and about $87-100 \%$ crenocytes by day 28 ps. Our findings was in line with the work of Ibrahim et al. (2016) on human pRBC where the reversible spherocytes were seen by day 14 ps, whereas this study showed about $87-100 \%$ irreversible crenocytes by day 28 , Ibrahim's work showed a $100 \%$ crenocytes by day 42 ps. This faster degeneration of canine stored blood could be attributed to progressive increase in erythrocyte size due to influx and accumulation of extracellular sodium ion in the cytosol as previously described by Okereke et al. (2020) and Udegbunam et al. (2020). Discoid shape of red blood cell influences its resistance to membrane distortions owing to a special organization of the membrane-skeleton system. This particular proûle maximizes the surface to volume ratio and thus may expedite diffusion and exchange. It is seen that during storage, red blood cells gradually loses the normal morphology of discoid shape and progress to spherocytes, with decreased surface area to volume ratio (Cluitmans et al., 2012) as a result of increased reactive oxygen species
(ROS) and decreased antioxidant defence mechanism leading to oxidation and degradation of these proteins. These ROS has known cytotoxic effects (Hess, 2010) and can cross-link erythrocyte membrane phospholipids and proteins (Hoehn et al., 2015). As membrane proteins are lost coupled with increasing ROS, ion pumps begin to fail causing the starving RBC's to swell as a result of influx of fluids. The erythrocytes will then take on a more spherical or hemispherical appearance shifting into numerous nondeformable protrusions of cellular membrane sticking out in all directions (Hess, 2010). These changes could be due to the continued biochemical, biomechanical and haematological alterations in the stored blood over time.

Red cell vitality was done in this study with trypan blue which in biosciences, it is used as a vital stain to selectively colour dead tissues or cells blue (Cunbo et al., 2017). Trypan blue stain for erythrocytes can also be termed dye exclusion method. Here, live cells with intact membranes are not coloured because they are selective to compounds that pass through them. In membrane compromised or dead cells, the trypan blue passes the membrane with the cell appearing blue colour under the microscope (Klaus et al., 2005). This work revealed blue staining erythrocytes by day $21 \mathrm{ps}$. Post storage days 0,7 and 14 revealed live cells (as seen in Plates 1, 2 and 3 respectively). However, by day 21 post

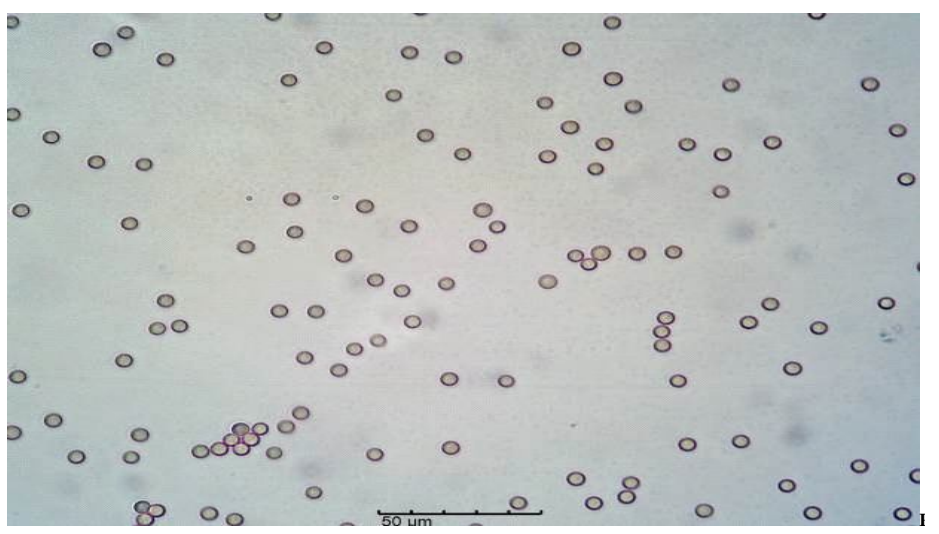

Plate 1: Day 0 showed that $100 \%$ of the cells remained unstained indicating they are still live. x400 magnification under light microscopy

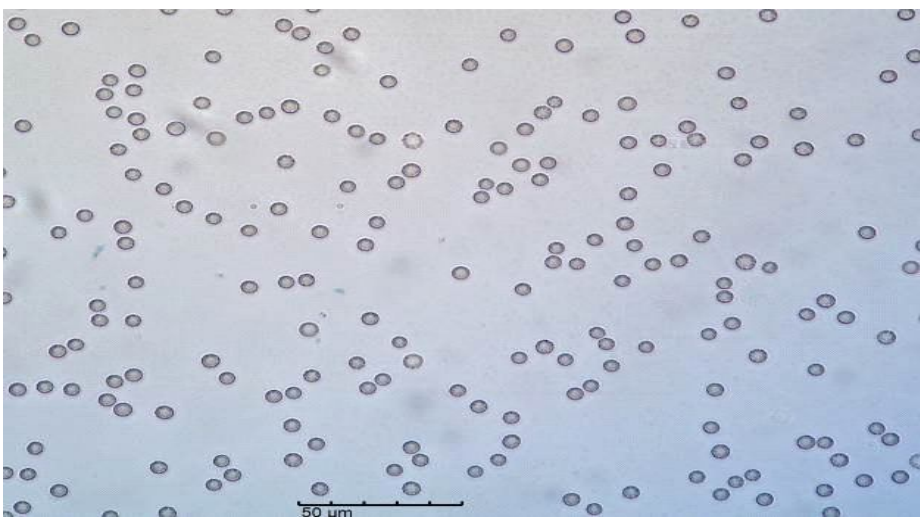

Plate 2: Day 7 showed that $100 \%$ of the cells remained unstained indicating they are still live. x400 magnification under light microscopy 
storage day, there were clusters of blue stained cells indicating presence of deformed/ dead red cells (Plate 4). This shows that with vital staining technique, compromised cells or dead cells was evident by day 21 with greater percentage by day 28 ps and day 35 ps as seen in Plates 5 , 6,7 . In as much as no documentation in literature has used this technique to actually study morphological changes associated with SCB in CPDA-1, we suggest that this could form a baseline study and the cause be attributed to the oxidative changes and distortion of membrane skeleton system of the erythrocytes (Uzoigwe, 2006).

Anesthesiologists and surgeons often estimate intraoperative blood loss by simple observation, which can offer wide-ranging values. This often leads to poor management with the transfusion of blood, blood products and fluids in the perioperative patient. Intra operative blood loss was

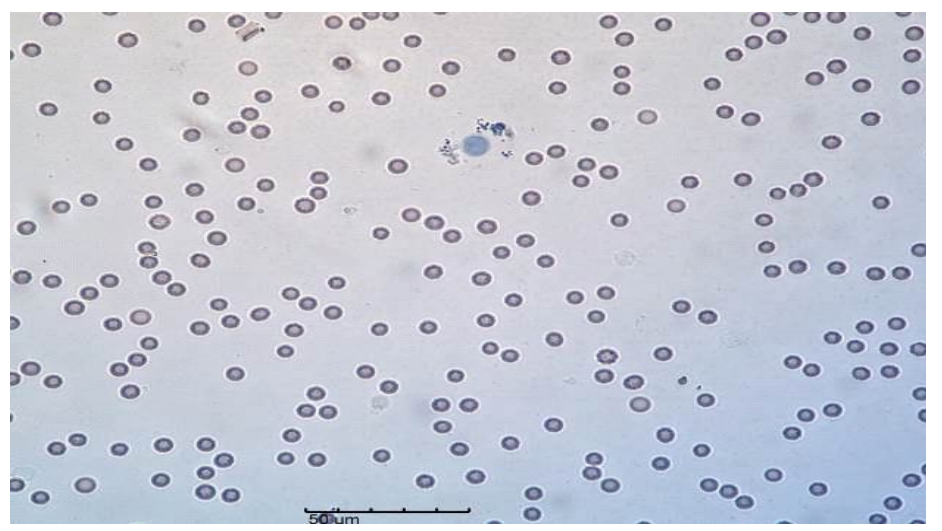

Plate 3: Day 14 showed greater percentage of the cells remained unstained indicating they are still live. x400 magnification under light microscopy.

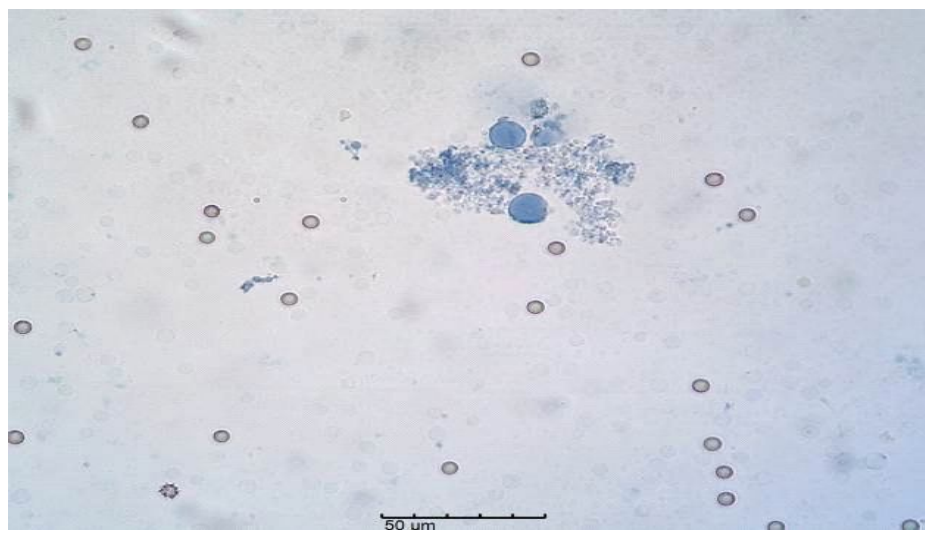

Plate 4: Day 21 showed few live cells with much clustered staining of cells (deformed/dead cells). x400 magnification under light microscopy

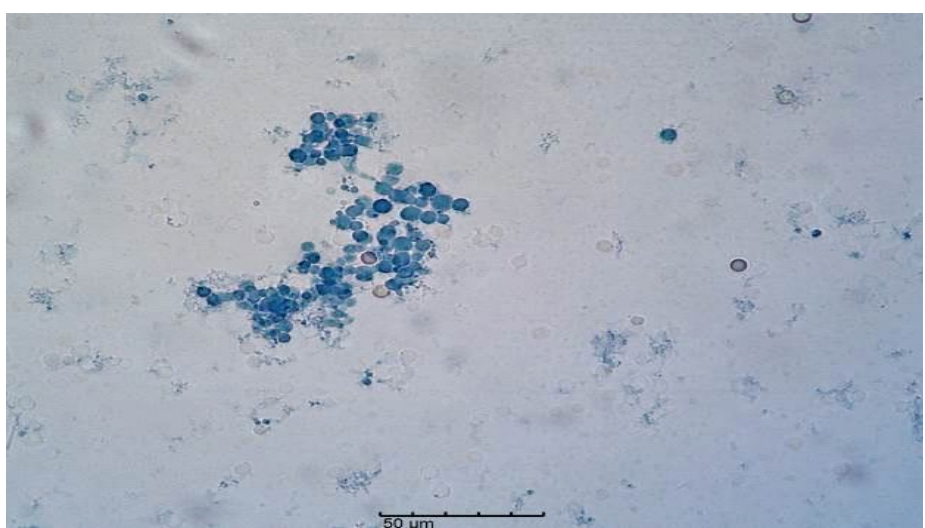

Plate 5: Day 28 showed greater percentage of the cells are clustered and stained (deformed/dead cells). x400 magnification under light microscopy 


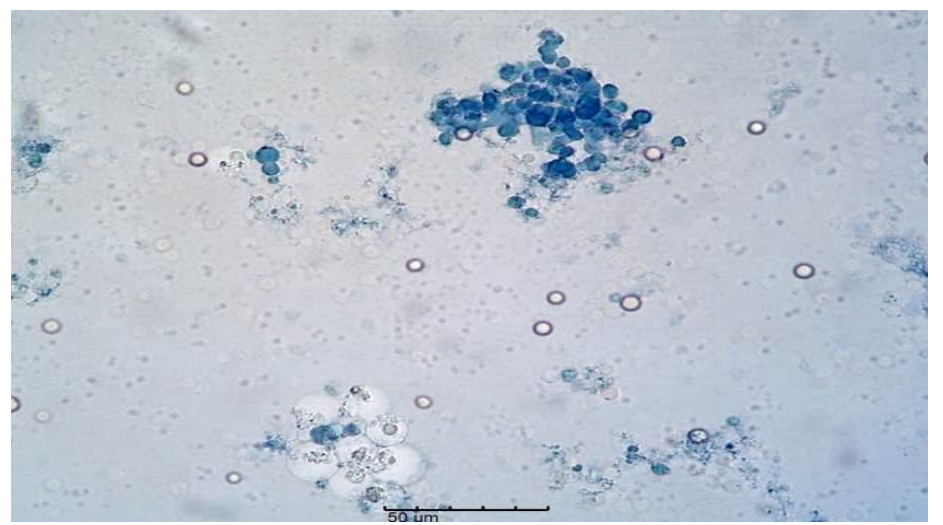

Plate 6: Day 28 showed greater percentage of the cells are clustered and stained (deformed/dead cells). x400 magnification under light microscopy.

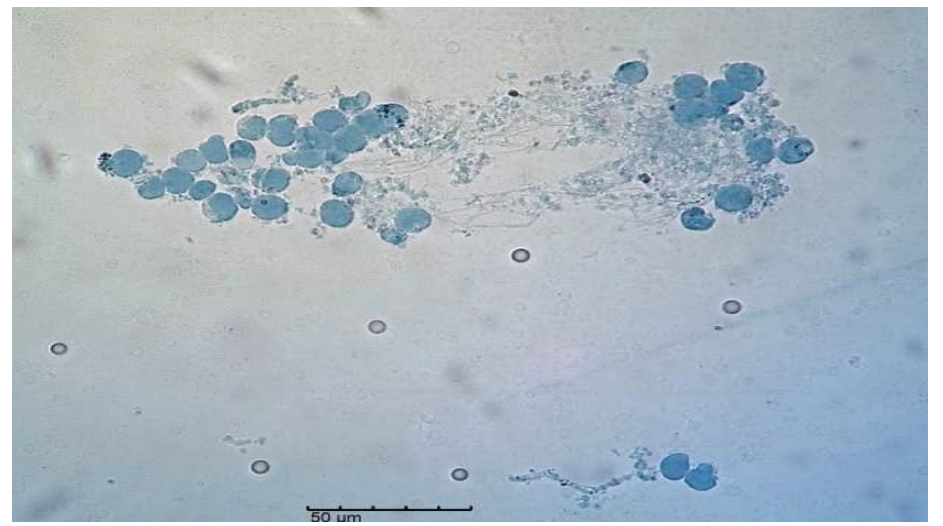

Plate 7: Day 35 showed greater percentage of the cells are clustered and stained (deformed/dead cells). x400 magnification under light microscopy.

estimated using the gravimetric method as against the Spectrophotometric method which though was more reliable but clinically impractical. (Dominic et al, 2015). Under estimation of blood loss can lead to unnecessary transfusion practices. On the other hand, Udegbunam et al. (2009) documented the need for anaesthesiologist and surgeons to consider the anaesthetic protocol used with respect to the nature of surgery been done. They argued that in surgical procedures such as splenectomy, some anaesthetic agents such as diazepam, ketamine and midazolam have the high tendency of causing increase in splenic volume where the blood cells are sequestrated in the spleen. Also, the use of barbiturates such as pentobarbitone, sodium amytal, pentothal have all also shown to cause increase in splenic size following administration (Hausner et al., 1938). Though no report in literature exist on the effects of atropine and xylazine on the splenic size following administration, ketamine is known to have a vasorelaxant effect which could cause an increase in splenic size of dogs following administration (Udegbunam et al., 2009). Findings shown in Table 3, however confirms the effect of ketamine administration on splenic size and validates the need for anaesthesiologist and surgeons to routinely estimate the volume of blood lost during each procedure.
Haldane et al. (2004), proposed that the goal for blood transfusion would be to achieve 25-30 percent hematocrit in recipient dogs. Based on the information from Haldane and other researchers on haematocrit selection and the knowledge that no literature documented the clinical trial on the use of very old blood for transfusion therapy in order to achieve desired haematocrit, this work was designed to clinically validate the claims of Haldane and other researchers. This study also tried to reveal that following the alterations associated with stored blood, if prolonged stored blood when used for transfusion will achieve the desired haematocrit as compared with when fresh blood is used. The findings of this study showed that 4 day old blood was able to achieve 15\% increase (from $31 \%$ to $46 \%$ ) in haematocrit even when the desired haematocrit was 39\% with $120 \mathrm{ml}$ of blood. The use of 14 day old blood was also able to achieve a $7 \%$ increase (30\% to $37 \%$ ) (Table 2 ) in haematocrit which agreed with the desired haematocrit. The use of 21 day old blood recorded a significant increase from the haematocrit 24 hours post transfusion (31.7\%) without a non-significant percentage desired haematocrit increase $(33.7 \%)$ while 28 day old blood usage caused significant decrease of haematocrit 24 hours post transfusion $(27 \%$ to $25.3 \%$ ) and desired haematocrit (29\%) (Table 2). This could 
Time Dependent Erythrocyte Morphometric Changes of Prolonged Stored Blood and its Effect on Target Post-transfusion...

Table 2: Mean \pm SEM of haematocrit before and after splenectomy, 24 hours post transfusion, desired haematocrit and percentage change in haematocrit following transfusion.

\begin{tabular}{|c|c|c|c|c|c|c|c|c|}
\hline Group & $\begin{array}{c}\text { Weight } \\
(\mathrm{kg})\end{array}$ & $\begin{array}{l}\text { Volume } \\
\text { (ml) }\end{array}$ & $\begin{array}{l}\text { Donor } \\
\text { HCT (\%) }\end{array}$ & $\begin{array}{c}\text { Pre-splenectomy } \\
\text { Recipient } \\
\text { HCT (\%) }\end{array}$ & $\begin{array}{c}\text { Post-splenectomy } \\
\text { Hct (\%) } \\
-6 \text { Hrs PS }\end{array}$ & $\begin{array}{c}\text { Desired } \\
\text { Recipients } \\
\text { Hct (DRH) } \\
(\%)\end{array}$ & $\begin{array}{c}\text { Post-splenectomy } \\
\text { Hct (PSH-PT) } \\
(\%)-24 \\
\text { Hrs PT }\end{array}$ & $\begin{array}{c}\text { Percentage } \\
\text { PSH-PT Hct } \\
\text { change } \\
\text { from DRH }\end{array}$ \\
\hline I & $7.2 \pm 1.4$ & $* * *$ & $* * *$ & $40.3 \pm 0.3^{a}$ & - & - & - & - \\
\hline II & $6.8 \pm 1.6$ & $120.0 \pm 0.0$ & $42.3 \pm 1.9^{a}$ & $40.3 \pm 0.3^{a}$ & $30.7 \pm 3.5^{\mathrm{a}}$ & $39.7 \pm 4.7$ & $46.7 \pm 4.3^{a}$ & +7 \\
\hline III & $8.8 \pm 0.9$ & $120.0 \pm 0.0$ & $41.0 \pm 0.6^{a}$ & $42.7 \pm 3.7^{a}$ & $21.7 \pm 0.9^{b}$ & $37.3 \pm 2.0$ & $37.3 \pm 3.2^{\mathrm{b}}$ & 0 \\
\hline IV & $7.8 \pm 0.4$ & $120.0 \pm 0.0$ & $42.3 \pm 1.5^{\mathrm{a}}$ & $43.0 \pm 2.9^{a}$ & $31.0 \pm 0.6^{\mathrm{a}}$ & $29.0 \pm 1.2$ & $31.7 \pm 1.7^{c}$ & +2.7 \\
\hline V & $8.2 \pm 0.7$ & $120.0 \pm 0.0$ & $39.3 \pm 0.3^{a}$ & $41.7 \pm 1.7^{\mathrm{a}}$ & $27.0 \pm 3.2^{\mathrm{a}}$ & $33.7 \pm 4.1$ & $25.3 \pm 2.0^{d}$ & -8.4 \\
\hline
\end{tabular}

HCT-haematocrit, Hrs- hours, PS- post splenectomy, PT- post transfusion.

Group I: splenectomised dogs (SD), Group II: SD transfused with 4 day old blood (DOB), Group III: SD transfused with 14 DOB, Group IV: SD transfused with $21 \mathrm{DOB}$, Group V: SD transfused with $28 \mathrm{DOB}$.

Superscripts ${ }^{a, b, c}$ in a column indicates significant difference $(P<0.05)$ between means obtained in the five groups.

Table 3: Showing blood loss estimation during splenectomy.

\begin{tabular}{lccc}
\hline $\begin{array}{l}\text { Splenic exanguination } \\
\text { method }\end{array}$ & $\begin{array}{c}\text { Weight of engorged } \\
\text { spleen (ENS) }\end{array}$ & $\begin{array}{c}\text { Weight of exanguinated } \\
\text { spleen (EXS) }\end{array}$ & ENS-EXS \\
\hline \multirow{3}{*}{ Gauze method } & $74.4 \pm 7.1^{\text {a }}$ & $38.1 \pm 3.2^{\mathrm{b}}$ & $36.3 \pm 5.3$ \\
& Weight of wet gauze & Weight of dry gauze & (WWG) \\
& $129.1 \pm 16.0^{\mathrm{a}}$ & $41.2 \pm 2.6^{\mathrm{b}}$ & WWG-WDG \\
& & $81.6 \pm 13.6$ \\
\hline
\end{tabular}

ENS- Engorged spleen; EXS- Exanguinated spleen.

superscripts ${ }^{a, b}$ in a row indicates significant difference $(P<0.05)$ between means.

be agreed to the progressive irreversible membrane cytoskeleton damage resulting to cell apoptosis (Kristensen and Feldman, 1995).

\section{CONCLUSION}

In conclusion, the findings of this study revealed progressive morphometric changes in stored blood by $14^{\text {th }}$ day of storage with marked $28^{\text {th }}$ day storage lesion in evaluating the viability of red cells. The morphometric findings correlated with the findings of the transfusion targets as blood stored up till $14^{\text {th }}$ day was able to achieve the desired haematocrit. This study revealed that days 4 and 14 old blood should be the hallmark for canine transfusion therapy as they achieved the target desired haematocrit. However, day 4 old blood gives an excellent result as no changes was observed by its storage time-point.

\section{ACKNOWLEDGEMENT}

Funded from the Tetiary Education Trust Fund Nigeria Institution Based Research (TETfund IBR; Ref. No. TETFUND/DR\&D/CE/UNI/NSUKKA/RP/VOL.I).

\section{Authors' contribution}

All authors contributed equally to this work.

\section{Competing interests}

The authors declare that they have no conflict of interest.

\section{REFERENCES}

Adili, N. and Melizi, M. (2014). Preliminary study of the influence of red blood cells morphometry on the species determinism of domestic animals. Veterinary World. 7(4): 219-223. doi: 10.14202/vetworld.2014.219-223.

Adili, N., Mohamed, M. and Hadj, B. (2016). Species determination using the red blood cells morphometry in domestic animals. Veterinary World. 9(9): 960-963. doi: 0.14202/vetworld. 2016.960-963

Cheesbrough, M. (2006). Hematological tests. In: District Laboratory Practice in Tropical Countries. Part 2. Second edition. Cambridge University Press. Cambridge. UK; pp 268-347.

Cluitmans, J.C.A., Hardeman, M.R., Dinkla, S., Brock, R. and Bosman, G.J.C.G.M. (2012). Red blood cell deformability during storage: towards functional proteomics and metabolomics in the Blood Bank. Blood Transfusion. 10(supplement 2): s12-s18. doi: 10.2450/2012.004S

Cunbo, L., Zheming, L., Shuang, X., Pengchong, J., Rui, Y., Mincai, C., Fen, H., Romano, A.R., Xinzheng, Z., Leiting, P. and Jingjun, X. (2017). Protection of the biconcave proûle of human erythrocytes against osmotic damage by ultravioletA irradiation through membrane-cytoskeleton enhancement. Citation: Cell Death Discovery. 3: 17040; doi: 10.1038/ cddiscovery.2017.40

Dominic, J.V., Richard, M.R., Michael, R.F., Guy, L.W. and Joseph, M.V. (2015). Blood Density Is Nearly Equal to Water Density: A Validation Study of the Gravimetric Method of Measuring Intraoperative Blood Loss. Journal of Veterinary Medicine. 152730. doi: 10.1155/2015/152730 
Haldane, S., Roberts, J., Marks, S.L. and Raffe, M.R. (2004). Transfusion Medicine. Compendium of Continuing Education for the Practicing Veterinarian. 26: 502518

Hausner, E., Essex, H.E. and Mann, F.C. (1938). Reontgenologic observations of the spleen of the dog under ether, sodium amytal, pentobarbital sodium and pentothal sodium anaesthesia. American Journal of Physiology. 121: 387391. doi: 10.1152/ajplegacy.1938.121.2.387.

Hess, J.R. (2010). Red cell changes during storage. Transfusion and Aphersis Science. 43(1): 51-9. doi: 10.1016/j. transci. 2010.05.009.

Hoehn, R.S., Peter, L.J., Alex, L.C., Michael, J.E. and Timothy, A.P. (2015) Molecular mechanisms of erythrocyte aging. Biological Chemistry 396(6-7): 1-24. doi: 10.1515/hsz2014-0292.

Hogman, C.F., Knutson, F. and Loof, H. (1999). Storage of whole blood before separation: The effect of temperature on red cell 2,3-DPG and the accumulation of lactate. Transfusion. 39(5): 492-497. doi: 10.1046/j.1537-2995. 1999.39050492.x.

Ibrahim, K.I.R. (2008). Histological study of effects of storage duration and temperature on the rabbits blood cells. The Egyptian Journal of Hospital Medicine. 30: 14-24.

Ibrahim, M., Asma, A.M., Khuloud, M.N., Noora, A.K. and Tameem, H. (2016). Time Dependent Assessment of Morphological Changes: Leuko-depleted Packed Red Blood Cells Stored in SAGM. BioMed Research International. 4529434. doi: 10.1155/2016/4529434.
Klaus, H., Peter, M., Wolfgang, R., Roderich, R., Klaus, K. and Aloys, E. (2005). "Azo Dyes". Ullmann's Encyclopedia of Industrial Chemistry. Ullmann's Encyclopedia of Industrial Chemistry. Weinheim: Wiley-VCH.

Kristensen, A.T. and Feldman, B.F. (1995). General principles of small animal blood component administration. Veterinary Clinics of North America: Small Animal Practice. 25(6): 1277-1290. doi: 10.1016/S0195-5616(95)50154-8.

Okereke, H.N., Udegbunam, R.I., Nwobi, L.G., Ezeobialu, H.T. and Udegbunam, S.O. (2020). In vitro assessment of timedependent changes in red cell cytoplasmic antioxidants of donkey blood preserved in citrate phosphate dextrose adenine 1 anticoagulant. Veterinary World. 13(4): 726-730. doi: 10.14202/vetworld.2020.726-730.

Udegbunam, R.I., Njaka, C.S., Okereke, H.N. and Udegbunam, S.O. (2020). Comparative evaluation of the in-vitro viability of canine and human blood preserved in citrate phosphate dextrose adenine-1 anticoagulated blood bag. Indian Journal of Animal Research. 54(5): 549-552 doi: 10. 18805 /ijar.B-1039.

Udegbunam, R.I., Umeh, L.A. and Udegbunam, S.O. (2009). The effects of Ketamine hydrochloride on the erythrocytic indices of splenectomized dogs. Animal Science Reporter. 3(3): 114-117.

Uzoigwe, C. (2006). The human erythrocyte has developed the biconcave disc shape to optimise the ûow properties of the blood in the large vessels. Medical Hypotheses. 67(5): 1159-1163. doi: 10.1016/j.mehy.2004.11.047.

Wehrli, G. (2012). Blood banking and transfusion medicine for the nephrologist. Seminars in Dialysis. 25(2): 114-118. doi: 10.1111/j.1525-139X.2011.01021.x. 